\title{
The Impact of Primary Care Physicians on Follow-up Care of Underserved Breast Cancer Survivors
}

\author{
Rose C. Maly, MD, MSPH, Yihang Liu, MA, MS, MD, Allison L. Diamant, MD, MSHS, \\ and Amardeep Thind, $M D, P b D$
}

Purpose: To investigate the impact of the involvement of primary care physicians (PCPs) on the receipt of preventive follow-up care after a breast cancer (BC) diagnosis among a low-income population.

Methods: Multiple logistic regression analyses were performed to identify potential factors associated with receipt of preventive care among 579 low-income women with BC. The main outcome variables at 36 months after BC diagnosis were receipt of annual mammography, Papanicolaou smear in the past 2 years, and ever had colonoscopy for those who were at least 50 years old. The main independent variable was type of provider visit in the past 12 months.

Results: Women with a PCP visit only or both PCP and surgeon/cancer specialist visits in the past 12 months were more likely to have had annual mammography (adjusted odds ratio [AOR], 2.67; $P=.109$ and A0R, 2.20, $P=.0008$, respectively), a Papanicolaou smear in the past 2 years (AOR, $2.90 ; P=.04$ and AOR, 2.24, $P=.009$, respectively), and colonoscopy (AOR, $2.99 ; P=.041$ and AOR, $2.17 ; P=.026$, respectively) than those who only visited surgeons/cancer specialists. Indeed, women who saw only a PCP for their follow-up care had the highest odds ratio of receiving each clinical care service.

Conclusions: The involvement of PCPs in the medical care of low-income BC survivors results in better preventive follow-up care. Getting PCPs involved in the care of cancer survivors might be particularly pertinent for low-income populations because of lower costs and ease of access compared with cancer specialist-provided care. (J Am Board Fam Med 2013;26:628-636.)

Keywords: Breast Cancer, Low Income Population, Primary Care Physicians, Quality of Health Care, Women's Health

Early detection and improved treatment have dramatically increased the life expectancy of women with breast cancer (BC), leading to overall 5-year survival rates of $98 \%$ for local-stage disease and $84 \%$ for regional-stage

\footnotetext{
This article was externally peer reviewed.

Submitted 21 December 2012; revised 8 April 2013; accepted 16 April 2013.

From the Department of Family Medicine (RCM, YL) the Department of Medicine, Division of General Internal Medicine and Health Services Research (ALD), David Geffen School of Medicine at the University of California-Los Angeles, Los Angeles; and the Departments of Family Medicine and Epidemiology and Biostatistics, University of Western Ontario, London, Ontario, Canada (AT).

Funding: This study was funded by the American Cancer Society (no. TURSG-02-081), the California Breast Cancer Research Program (no. 7PB-0070), and the National Cancer Institute (no. 1R01CA119197-01A1). RCM was also supported by the National Cancer Institute (no. R01CA140481-01A1).

Conflict of interest: none declared.

Corresponding author: Rose C. Maly, MD, MSPH, Department of Family Medicine, David Geffen School of Medicine at UCLA, 10880 Wilshire Blvd, Ste. 1800, Los Angeles, CA 90095-7087 (E-mail: rmaly@mednet.ucla.edu).
}

disease. ${ }^{1,2}$ Women with BC now represent the largest female cancer survivor group in the United States. ${ }^{3}$ This is creating new challenges for the health care system, with medical concern shifting from initial treatment to survivorship and the responsibility for care shifting from oncologists to primary care providers. ${ }^{4}$

Long-term BC survivors are at an increased risk of developing a second primary cancer or recurrent disease in the affected breast, which makes follow-up care an essential part of cancer survivorship. ${ }^{5-7}$ Cancer patients traditionally tend to visit their oncologists for routine follow-up after completing cancer treatments. ${ }^{8-10}$ However, with the increased populations of patients with newly diagnosed breast cancer and cancer survivors, there is concern about the capacity for oncologists to provide appropriate care and meet the needs of cancer

See Related Commentary on page 623. 
patients in the future. ${ }^{11,12}$ In addition, there is concern about possible deficiencies in non-cancer-related care that cancer survivors receive from oncologists because oncologists may be too focused on cancer-specific issues and overlook other primary care services. ${ }^{13-15}$

In recognition of the importance of the involvement of primary care physicians (PCPs) in ongoing cancer care, the American Society of Clinical Oncology published guidelines for BC survivors, suggesting that PCPs take greater responsibility for survivorship care. ${ }^{16}$ This highlights the need for better information about the participation of PCPs in BC survivorship care, yet research in this area is limited.

There are a handful of studies that compare the follow-up care provided by PCPs to that provided by oncologists for breast cancer survivors. Results of these studies showed no difference in recurrence detection outcomes or receipt of preventive care between survivors followed up by PCPs and survivors followed up by oncologists. ${ }^{10,17,18}$ Another study reported PCP-centered follow-up is superior to oncologist-centered follow-up in terms of recommended preventive care. ${ }^{14}$ However, these studies have limitations, including sample populations that were either restricted to certain age groups, ${ }^{14}$ living in areas outside of the United States, ${ }^{17}$ or insured by Medicare. ${ }^{19}$ It is important to note that none of these studies examined follow-up care among medically underserved, low-income, and/or uninsured women.

The unequal distribution of the financial burden of breast cancer across socioeconomic groups has been well documented, ${ }^{19-21}$ and low-income, less educated women may be at particular risk for poorer survivorship care because of financial hardship and poor access to medical care. An examination of PCPs' involvement in survivorship care among low-income women may assist in identifying effective and cost-efficient ways to deliver optimal care among vulnerable BC patient populations.

The objective of this study was to identify potential factors associated with receipt of appropriate follow-up care among low-income, medically underserved women with $\mathrm{BC}$, in particular with regard to preventive services. This is the first such study performed in a low-income population of women with BC. We were specifically interested in investigating the effect of PCPs' involvement in the receipt of follow-up care.

\section{Methods \\ Study Sample}

This is a longitudinal observational study. The details of the study design and sample have been described previously. ${ }^{22}$ This study used data compiled from longitudinal surveys of low-income women living in California, aged $\geq 18$ years, newly diagnosed with $\mathrm{BC}$, and enrolled in the California Breast and Cervical Cancer Treatment Program (BCCTP) between February 2003 and September 2005. The BCCTP is funded in part by Medicaid and by the state of California to provide treatment for breast and cervical cancer for uninsured and underinsured, low-income women $(\leq 200 \%$ of the federal poverty level). The study was approved by the UCLA Human Subjects Protection Committee.

Eligible women were interviewed by phone in English or Spanish at 6,18, and 36 months after their diagnosis of BC. A total of 921 women were initially recruited for the baseline interview at 6 months, for a $61 \%$ response rate. Compared with survey responders, nonresponders were older (mean ages, 52 vs. 50 years; $P<.0001$ ), more likely to be Asian/Pacific Islander and less likely to be Latina or white $(11.6 \%, 37.6 \%$, and $26.5 \%$ vs. $7.4 \%, 53.4 \%$, and $31.7 \%$, respectively; $P<.05$ ). Of the 921 women who participated in the first interview, response rates at 18 and 36 months were $86 \%$ and $73 \%$, respectively.

We also obtained and abstracted detailed clinical information from patients' medical records 18 months after $\mathrm{BC}$ diagnosis, including clinical information about tumor characteristics and staging and details of treatment. We had 800 patients $(87 \%)$ consent to the medical record review and were able to successfully retrieve and abstract medical records for $84 \%(n=776)$ of this group. The interrater reliability between abstractors for data on BC characteristics and treatment data ranged from 0.68 to 1.00 , indicating good to excellent agreement.

Women who were diagnosed with stage 0 -III BC, had completed all the 6-, 18-, and 36-month surveys, and had visited the doctor's office at least once during the past 12 months, as reported at the 36-month survey, were identified for inclusion in this study. A total of 579 subjects were included in 
the analyses. A subset of 371 subjects who were at least 50 years old was identified for the analysis of the receipt of colonoscopy.

\section{Measures}

The main outcome variables were receipt of follow-up care 36 months after BC diagnosis, including annual mammography, Papanicolaou smear in the past 2 years, and ever had colonoscopy (for those who were at least 50 years old). All these variables were measured by patient self-report in the 36-month survey.

The main independent variable was type of health care provider visited in the 12 months before the 36-month point after $\mathrm{BC}$ diagnosis, including surgeons, cancer specialists, and PCPs. Only those participants who had visited a provider at least once in the past 12 months were included in the analyses. These patients were categorized into 3 groups: having had a PCP visit only, a surgeon/cancer specialist visit only, or both PCP and surgeon/cancer specialist visits.

Other independent and potentially confounding variables were patient sociodemographic characteristics, comorbidities, and financial adequacy measured at the 6-month baseline survey. The existence of major comorbidities was measured using the Charlson Comorbidity Index for patient selfreport as adapted by Katz et $\mathrm{al}^{23}$ and was dichotomized into one or more comorbidities versus none. Potential life burden pertinent to low-income women was measured by adequacy of financial resources by asking, "Do you have enough money to cover your needs?" Competing life needs ("In the past year, have you ever had to go without needed medical care because you had to spend money for food, clothing, housing or transportation") and ease of access to medical care (somewhat easy/very easy vs. somewhat difficult/very difficult) were measured at the 36-month survey. We also included information on tumor stage from the medical records.

Language and acculturation can serve as significant barriers to optimal communication. Therefore, among Latinas, language-based acculturation was determined by the 5-item Marin Acculturation Scale. ${ }^{24}$ The internal consistency reliability of this scale was 0.99 in the studied sample. A "more acculturated" Latina was defined as being equally or more comfortable or conversant with English than Spanish; "less acculturated" was defined as being less comfortable or conversant with English than Spanish.

\section{Data Analysis}

Summary statistics, including means and percentages, were calculated to describe participants' demographic/clinical characteristics and other independent variables. A multivariate logistic regression model was then fit to investigate the effect of PCPs' involvement on the receipt of follow-up care 36 months after BC diagnosis, controlling for potential confounders. Multicollinearity was examined for all independent variables and was found not to be a problem. The Hosmer-Lemeshow test indicated adequate fit of the multivariate logistic regression model. All statistical analyses were conducted using SAS software, version 9.1 (SAS, Inc., Cary, NC); 2 -sided $\alpha$ levels with $P$ values $<0.05$ were considered statistically significant.

\section{Results}

\section{Descriptive Statistics}

Overall, $80.8 \%$ of the sample had received annual mammography; this is higher than the $\mathrm{BC}$ screening rate $(72.4 \%)$ in the general population. ${ }^{25}$ However, screening examination rates for cervical cancer and colorectal cancer in our sample were lower than the rates in the general population $(79.3 \%$ vs. $83.0 \%$ and $49.6 \%$ vs. $58.6 \%$, respectively). ${ }^{25}$ Table 1 shows the descriptive statistics among the 579 women in the sample. At 36 months after BC diagnosis, most survivors were visiting both a PCP and surgeon/cancer specialist for their medical care (75.8\%). About 2 of 10 women had visited only surgeon/cancer specialists $(17.3 \%)$ in the past 12 months, and $7 \%$ of the women visited only a PCP. The sample predominately comprised less-acculturated Latinas (47.5\%), with whites accounting for approximately one-third (33.9\%). The average age was approximately 51 years, and about $41 \%$ had not graduated from high school. Slightly more than half were married or partnered.

With respect to medical characteristics, about one third of the sample had at least one comorbidity, and more than half were diagnosed either with stage II or stage III BC (62\%). More than $70 \%$ of the participants reported receiving adjuvant hormone therapy. 
Table 1. Descriptive Statistics of the Study Sample

$(\mathrm{n}=579)$

\begin{tabular}{|c|c|}
\hline Demographics & Value \\
\hline \multicolumn{2}{|l|}{ Age (years) } \\
\hline Mean (SD) & $51.2(9.1)$ \\
\hline Range & $25.0-85.0$ \\
\hline \multicolumn{2}{|l|}{ Ethnicity } \\
\hline White & $196(33.9)$ \\
\hline Less-acculturated Latina & $275(47.5)$ \\
\hline More-acculturated Latina & $33(5.7)$ \\
\hline African American & $25(4.3)$ \\
\hline Asian/Pacific Islander & $50(8.6)$ \\
\hline \multicolumn{2}{|l|}{ High school graduate } \\
\hline No & $235(40.6)$ \\
\hline Yes & $344(59.4)$ \\
\hline \multicolumn{2}{|l|}{ Married/partnered } \\
\hline No & $284(49.1)$ \\
\hline Yes & $295(51.0)$ \\
\hline \multicolumn{2}{|l|}{ Comorbidity } \\
\hline None & $409(70.6)$ \\
\hline Any & $170(29.4)$ \\
\hline \multicolumn{2}{|l|}{ Stage } \\
\hline 0 & $67(11.6)$ \\
\hline I & $152(26.3)$ \\
\hline II & $267(46.1)$ \\
\hline III & $93(16.1)$ \\
\hline \multicolumn{2}{|l|}{ Hormone therapy } \\
\hline No & $168(29.0)$ \\
\hline Yes & $411(71.0)$ \\
\hline \multicolumn{2}{|l|}{ Financial adequacy } \\
\hline No & $358(61.8)$ \\
\hline Yes & $221(38.2)$ \\
\hline \multicolumn{2}{|l|}{$\begin{array}{l}\text { Did not get medical care because of } \\
\text { competing life needs }\end{array}$} \\
\hline No & $451(77.9)$ \\
\hline Yes & $128(22.1)$ \\
\hline \multicolumn{2}{|l|}{ Doctor visit group } \\
\hline PCP only & $40(7.0)$ \\
\hline Surgeon/cancer specialist only & $100(17.3)$ \\
\hline Both PCP and surgeon/cancer specialist & $439(75.8)$ \\
\hline \multicolumn{2}{|l|}{ Access to medical care } \\
\hline Very easy/somewhat easy & $358(61.8)$ \\
\hline Very difficult/somewhat difficult & $221(38.2)$ \\
\hline
\end{tabular}

Data are $\mathrm{n}(\%)$ unless otherwise indicated.

PCP, primary care provider; SD, standard deviation.

The majority of the population reported financial hardship (62\%), and about 1 in 5 women had not been able to receive needed medical care because of competing life needs. Almost $40 \%$ of the participants reported somewhat/very difficult access to medical care.

\section{Factors Associated with Receipt of Follow-up Care}

In unadjusted analyses (Table 2), survivors who visited both a PCP and surgeon/cancer specialist were most likely to receive annual mammography $(83 \%)(P=.015)$, and survivors who visited only a PCP were most likely to have had a colonoscopy performed $(63.3 \%)(P=.0007)$. Survivors who visited only a surgeon/cancer specialist for follow-up care were least likely to receive each medical service.

Table 3 presents the results of the multivariate logistic regression models. After adjusting for potential confounders, women with a PCP visit only or both PCP and surgeon/cancer specialists visits in the past 12 months were more likely to have had annual mammography, a Papanicolaou smear in the past 2 years, and colonoscopy than those who visited only surgeon/cancer specialists. Indeed, women who saw only a PCP for their follow-up care had the highest odds of receiving each clinical care service among the 3 doctor visit groups, even though the difference for annual mammography was not significant.

Receiving adjuvant hormone therapy also was positively associated with annual mammography and having a Papanicolaou smear done in the past 2 years. In addition, both less-acculturated and moreacculturated Latinas were more likely to have had a Papanicolaou smear done in the preceding 2 years compared with their white counterparts. However, older women were less likely to have had a Papanicolaou smear during the past 2 years. Women with greater ease of access to medical care were more likely to receive a colonoscopy.

\section{Discussion}

Identifying the responsibilities of different providers in the coordination of care for cancer survivors has been greatly discussed in recent years. ${ }^{17,26-28}$ Cancer survivors in United States traditionally receive most of their cancer follow-up care from cancer specialists. ${ }^{9,29}$ However, the growing number of cancer patients and survivors along with the shortage of the oncologist workforce ${ }^{11,12}$ has highlighted the need to engage PCPs' participation in follow-up cancer care. In this study we examined the role of PCPs in BC survivors' follow-up care. It is the first such study performed in a low-income population of women with BC. Our findings indicate that, 36 months after $\mathrm{BC}$ diagnosis, survivors 
Table 2. Unadjusted Analysis of Preventive Care by Provider $(n=579)$

\begin{tabular}{lcccc}
\hline Preventive Care & PCP Only (\%) & $\begin{array}{c}\text { Surgeon/Cancer Specialist } \\
\text { Only (\%) }\end{array}$ & $\begin{array}{c}\text { Both PCP and Surgeon/Cancer } \\
\text { Specialist (\%) }\end{array}$ & $P$ Value* \\
\hline Annual mammography & 77.5 & 71.0 & 83.0 & .015 \\
Pap in the past 2 years & 77.5 & 73.0 & 80.9 & .207 \\
Colonoscopy & 63.3 & 27.6 & 52.3 & .0007 \\
\hline
\end{tabular}

${ }^{*} \chi^{2}$ Test.

Pap, Papanicolaou test; PCP, primary care provider.

were more likely to see their PCPs than exclusively visit cancer specialists. In addition, we found that survivors who had a PCP involved in their follow-up care seem to have received more appropriate care in terms of preventive services than those who visited only cancer specialists for their follow-up care.

Previous randomized trials have shown similar recurrence detection rates and health-related quality of life between BC survivors who were followed up by PCPs and those who were followed up by cancer specialists. ${ }^{10,17}$ Other studies indicate that, compared with follow-up by specialists, follow-up by PCPs results in better patient satisfaction and higher quality of non-cancer-related health care. ${ }^{15,30,31}$ Our study builds on previous research by demonstrating that follow-up care provided by PCPs results in higher quality of both BC-related and other cancer screening-related care.

In current practice, patients with breast cancer are typically seen by oncologists for routine follow-up during the first 5 years after completing cancer treatment. This study-at 3 years after BC diagnosis-demonstrates that PCPs are capable of providing high-quality preventive cancer care at an earlier stage of follow-up for BC cancer survivors. In fact, active and early involvement of PCPs in cancer care might be particularly beneficial to those who have chronic diseases, given the potential of interaction effects between cancer treatment and

Table 3. Multivariate Logistic Regression Analysis of Preventive Care by Patient Groups $(n=579)$

\begin{tabular}{|c|c|c|c|c|c|c|}
\hline & \multicolumn{2}{|c|}{ Annual Mammography } & \multicolumn{2}{|c|}{ Pap in the Past 2 Years } & \multicolumn{2}{|c|}{ Colonoscopy $(\mathrm{n}=371)$} \\
\hline & $\operatorname{AOR}(95 \% \mathrm{CI})$ & $\begin{array}{c}P \\
\text { Value }\end{array}$ & $\operatorname{AOR}(95 \% \mathrm{CI})$ & $\begin{array}{c}P \\
\text { Value }\end{array}$ & $\operatorname{AOR}(95 \% \mathrm{CI})$ & $\begin{array}{c}P \\
\text { Value }\end{array}$ \\
\hline Age $>50$ years & $1.34(0.86-2.11)$ & .200 & $0.29(0.18-0.47)$ & $<.0001$ & $1.03(0.99-1.07)$ & .095 \\
\hline Any comorbidity (yes)* & $1.49(0.89-2.47)$ & .127 & $0.71(0.45-1.12)$ & .148 & $1.30(0.82-2.05)$ & .269 \\
\hline Married/partnered (yes) & $1.42(0.89-2.27)$ & .140 & $1.35(0.85-2.15)$ & .208 & $0.96(0.61-1.53)$ & .870 \\
\hline High school graduate (yes) & $0.77(0.44-1.36)$ & .369 & $0.87(0.49-1.55)$ & .639 & $1.21(0.69-2.11)$ & .503 \\
\hline \multicolumn{7}{|l|}{ Ethnicity (reference: white) } \\
\hline African American & $0.99(0.36-2.74)$ & .985 & $1.71(0.60-4.89)$ & .315 & $1.38(0.42-4.53)$ & .593 \\
\hline Less-acculturated Latina & $1.73(0.94-3.18)$ & .077 & $2.76(1.50-5.08)$ & .001 & $0.72(0.40-1.30)$ & .273 \\
\hline More-acculturated Latina & $0.76(0.32-1.81)$ & .536 & $3.44(1.10-10.75)$ & .034 & $1.48(0.55-3.97)$ & .438 \\
\hline Other & $1.43(0.62-3.31)$ & .409 & $1.56(0.71-3.46)$ & .269 & $0.95(0.42-2.18)$ & .903 \\
\hline Stage III & $0.63(0.36-1.10)$ & .106 & $0.88(0.49-1.58)$ & .658 & $1.09(0.58-2.02)$ & .794 \\
\hline Hormone therapy (yes) & $1.65(1.04-2.62)$ & .033 & $1.98(1.23-3.18)$ & .0047 & $1.30(0.80-2.13$ & .296 \\
\hline \multicolumn{7}{|c|}{$\begin{array}{l}\text { Doctor visit group (reference: surgeon/cancer } \\
\text { specialist only) }\end{array}$} \\
\hline PCP only & $2.67(0.84-5.74)$ & .109 & $2.90(1.05-8.04)$ & .040 & $2.99(1.5-8.51)$ & .041 \\
\hline Both PCP and cancer specialist & $2.20(1.51-4.72)$ & .0008 & $2.24(1.22-4.10)$ & .009 & $2.17(1.10-4.30)$ & .026 \\
\hline Financial adequacy (yes) & $0.89(0.55-1.42)$ & .612 & $1.28(0.79-2.09)$ & .321 & $0.78(0.48-1.25)$ & .296 \\
\hline Competing life needs (yes) & $0.81(0.48-1.38)$ & .443 & $0.91(0.52-1.58)$ & .741 & $1.61(0.92-2.82)$ & .099 \\
\hline $\begin{array}{l}\text { Access to medical care (reference: very } \\
\text { difficult/somewhat difficult ) }\end{array}$ & $0.66(0.41-1.09)$ & .104 & $0.95(0.58-1.55)$ & .826 & $1.73(1.06-2.83)$ & .029 \\
\hline
\end{tabular}

*One or more major comorbidity vs. none.

AOR, adjusted odds ratio; CI, confidence interval; Pap, Papanicolaou test; PCP, primary care provider. 
comorbid conditions. ${ }^{32,33}$ In a recent study exploring PCPs' views of routine follow-up care of cancer survivors, the majority of the PCPs felt that they are better placed to provide psychosocial support to their patients than oncologists and were willing to assume exclusive follow-up cancer care within 2.5 to 3.5 years after treatment completion. ${ }^{34}$ Our study adds evidence to demonstrate that PCP involvement at an earlier stage leads to better follow-up preventive care for cancer survivors.

Similar to previous research, ${ }^{15}$ BC survivors in our study who were followed exclusively by cancer specialists were less likely to receive cervical and colon cancer screening. These results indicated that specialists might be too focused on the follow-up of the previously diagnosed cancer and overlook other necessary preventive cancer screenings. It is also reported that oncologists generally do not want to function in a primary care-like role and are reluctant to provide preventive services. ${ }^{35}$

Although some studies have reported that PCPs may tend to provide less cancer-specific surveillance than oncologists, ${ }^{15,36}$ our data show that PCPs' involvement in follow-up results in better breast cancer-specific care-in this case, surveillance mammography. Previous studies have shown that with proper guidelines, PCPs are more confident in taking a lead in cancer follow-up care. ${ }^{37,38}$ Many PCPs report a desire for more training and guidelines to provide care for long-term cancer survivors. ${ }^{39}$ However, few evidence-based guidelines for follow-up care for cancer survivors exist today, and non-cancer-related health concerns are rarely mentioned in these guidelines. In addition, patients and providers in different specialties have varying expectations about which providers continue to provide care after multimodality treatment is complete. ${ }^{40}$

Despite studies that have shown PCP-provided follow-up leads to similar or even superior results than follow-up provided by oncology specialists, ${ }^{10,14,17,19}$ findings suggest that many BC survivors have concerns about transferring of care to PCPs. ${ }^{17,29,41}$ Cheung et $\mathrm{al}^{29}$ reported that $91 \%$ of cancer survivors favored oncologist-centered follow-up, whereas only $33 \%$ of cancer survivors favored PCP-centered follow-up. Communication between oncologists and PCPs has been identified as a major weakness from the survivors' perspectives. $^{30}$
Limited communication between oncologists and PCPs can contribute to inefficiency and may expose survivors to suboptimal preventive health services. A recent study showed that more than half of PCPs rated the transfer of care from oncologist to PCP as poor. ${ }^{42}$ Many PCPs indicated they would be willing to provide follow-up care if given specific guidelines from the cancer specialist. ${ }^{29,42}$ A survivorship plan including a summary of treatment and long-term expectations and recommendation for the patient and PCP may be an efficient way to facilitate the transition. ${ }^{43,44}$ Other tools, such as improved access to patient records with electronic medical record systems, might also help to ease the transition.

We found that women of Latina ethnicity had a significantly higher odds of receiving a Papanicolaou smear than their white counterparts. This is in contrast to previous findings showing that Latinas were less likely to receive cervical cancer screening. ${ }^{45,46}$ However, our study mirrors the findings of several other studies of Latinas' higher odds of receiving Papanicolaou smears than non-Latina whites after controlling for confounders. ${ }^{4-50}$ Since it is well known that Latinas have a higher prevalence of cervical cancer than do white women, ${ }^{51}$ many programs targeting Latinas have sought to educate women about the importance of Papanicolaou smears. ${ }^{52-54}$ Latinas thus may benefit from public health efforts tailored to improve the utilization of cervical cancer screening.

Consistent with previous research, ${ }^{55,56}$ our finding indicated that women $>50$ years old were less likely to undergo cervical cancer screening with a Papanicolaou smear. We also found that hormone therapy was associated with an increased likelihood of the receipt of mammography and Papanicolaou smear. It is more likely that these women may have received more medical attention because of their concurrent hormone treatment. However, further studies are needed to investigate the mechanism behind these findings.

Several limitations exist in this study. First, the study was conducted in a sample of low-income, medically underserved women in a specific Medicaid BC treatment program in California; external generalizability of the findings to other low-income populations such as those in other states in the United States or those with other cancers may be limited. However, because all survivors had benefits covered by the BCCTP program, it removed 
reimbursement disparities as a potential confounder of the findings. Second, the outcome measure "ever had colonoscopy" might not truly reflect the follow-up care after BC diagnosis because it might include health care completed before diagnosis. Third, the quality of our data depends on the accuracy of patient self-report, and thus recall bias may be an issue. However, a recently published article about this study population reported that self-reporting of key treatment and prognostic information is relatively accurate among low-income women with BC. ${ }^{57}$

\section{Conclusions}

This study is the first such study performed in a low-income, underserved population of $\mathrm{BC}$ patients. Our findings demonstrate that PCPs' involvement in the medical care of low-income BC survivors results in better follow-up care, particularly with regard to cancer preventive services. Getting PCPs involved in the care of cancer survivors might be particularly pertinent for low-income populations because of lower costs and ease of access compared with care provided by cancer specialists. With the projected shortage in the oncology workforce ${ }^{11,12}$ and the growing number of cancer survivors, PCP involvement in cancer follow-up care should be promoted as a cost-efficient way to deliver optimal care, especially among vulnerable populations.

\section{References}

1. Soerjomataram I, Louwman MWJ, Bibot JG, Roukema JA, Coebergh JWW. An overview of prognostic factors for long-term survivors of breast cancer. Breast Cancer Res Treat 2008;107:309-30.

2. Cancer facts and figures 2008. Atlanta, GA: American Cancer Society, 2008. Available from: http:// www.cancer.org/research/cancerfactsstatistics/cancer factsfigures2008/index. Accessed September 10, 2013.

3. Burstein HJ, Winer E. Primary care for survivors of breast cancer. N Engl J Med 2000;343:1086-94.

4. Hewitt M, Greenfield S, Stovall E. From cancer patient to cancer survivor: lost in transition. Washington, DC: National Academies Press; 2006.

5. Bosco JL, Lash TL, Prout MN, et al. Breast cancer recurrence in older women five to ten years after diagnosis. Cancer Epidemiol Biomarkers Prev 2009; 18:2979-83.

6. Bernstein JL, Lapinski RH, Thakore SS, Doucette JT, Thompson WD. The descriptive epidemiology of second primary breast cancer. Epidemiology 2003;14:552-8.

7. Earle CC. Failing to plan is planning to fail: improving the quality of care with survivorship care plans. J Clin Oncol 2006;24:5112-6.

8. Mariscotti J. A delicate dance: negotiating the doctor-patient relationship during cancer treatment. Oncologist 2008;13:1205-6.

9. Mayer EL, Gropper AB, Neville BA, et al. Breast cancer survivors' perceptions of survivorship care options. J Clin Oncol 2012;30:158-63.

10. Grunfeld E, Mant D, Yudkin P, et al. Routine follow up of breast cancer in primary care: randomized trial. BMJ 1996;313:665-9.

11. Warren JL, Mariotto AB, Meekins A, Topor M, Brown ML. Current and future utilization of services from medical oncologists. J Clin Oncol 2008;26: 3242-7.

12. Erikson C, Salsberg E, Forte G, Bruinooge S, Goldstein $M$. Future supply and demand for oncologists: challenges to assuring access to oncology services. J Oncol Pract 2007;3:79-86.

13. Snyder CF, Earle CC, Herbert RJ, et al. Preventive care for colorectal cancer survivors: a 5-year longitudinal study. J Clin Oncol 2008;26:1073-9.

14. Earle CC, Burstein HU, Winer EP, Weeks JC. Quality of non-breast cancer health maintenance among elderly breast cancer survivors. J Clin Oncol 2003;21:1447-51.

15. Earle C, Neville BA. Under use of necessary care among cancer survivors. Cancer 2004;101:1712-9.

16. Khatcheressian JL, Wolff AC, Smith TJ, et al. American Society of Clinical Oncology 2006 update of the breast cancer follow-up and management guidelines in the adjuvant setting. J Clin Oncol 2006;24: 5091-7.

17. Grunfeld E, Levine MN, Julian JA, et al. Randomized trial of long-term follow-up for early-stage breast cancer: a comparison of family physician versus specialist care. J Clin Oncol 2006;24:848-55.

18. Snyder CF, Frick KD, Kantsiper ME, et al. Prevention, screening, and surveillance care for breast cancer survivors compared with controls: changes from 1998 to 2002. J Clin Oncol 2009;27:1054-61.

19. Herndon JE 2nd, Kornblith AB, Holland JC, Paskett ED. Effect of socioeconomic status as measured by education level on survival in breast cancer clinical trials. Psychooncology 2013;22:315-23.

20. Weaver KE, Rowland JH, Bellizzi KM, Aziz NM. Forgoing medical care because of cost: assessing disparities in healthcare access among cancer survivors living in the United States. Cancer 2010;3493-504.

21. DeSantis C, Jemal A, Ward E. Disparities in breast cancer prognostic factors by race, insurance status, and education. Cancer Causes Control 2010;21: 1445-50.

22. Chen JY, Diamant AL, Thind A, Maly RC. Determinants of breast cancer knowledge among newly diag- 
nosed, low-income, medically underserved women with breast cancer. Cancer 2008;112:1153-61.

23. Katz JN, Chang LC, Sangha O, Fossel AH, Bates DW. Can comorbidity be measured by questionnaire rather than medical record review? Med Care 1996;34:73-84.

24. Marin G, Sabogal F, Marin B, et al. Development of a short acculturation scale for Hispanics. Hosp J Behav Sci 1987;9:183-205.

25. Centers for Disease Control and Prevention. Cancer Screening-United States, 2010. MMWR Morb Mortal Wkly Rep 2012;61:41-5.

26. Hollowell K, Olmsted CL, Richardson AS, et al. American Society of Clinical Oncology-recommended surveillance and physician specialty among long-term breast cancer survivors. Cancer 2010;116: 2090-8.

27. Aubin M, Vézina L, Verreault R, et al. Patient, primary care physician and specialist expectations of primary care physician involvement in cancer care. J Gen Intern Med 2012;27:8-15.

28. Grunfeld E, Mant D, Vessey MP, Fitzpatrick R. Specialist and general practice views on routine follow-up of breast cancer patients in general practice. Fam Pract 1995;12:60-5.

29. Cheung WY, Neville BA, Cameron DB, et al. Comparisons of patients and physician expectations for cancer survivorship care. J Clin Oncol 2009;27: 2489-95.

30. Mao JJ, Bowman MA, Stricker CT, et al. Delivery of survivorship care by primary care physicians: the perspective of breast cancer patients. J Clin Oncol 2009;27:933-8.

31. Grunfeld E, Fitzpatrick R, Mant D, et al. Comparison of breast cancer patient satisfaction with follow-up in primary care versus specialist care: results from a randomized controlled trial. Br J Gen Pract 1999;49:705-10.

32. Nagel G, Wedding U, Rohrig B, Katenkamp D. The impact of comorbidity on the survival of postmenopausal women with breast cancer. J Cancer Res Clin Oncol 2004;11:664-70.

33. Land LH, Dalton SO, Jensen MB, Ewertz M. Influence of comorbidity on the effect of adjuvant treatment and age in patients with early-stage breast cancer. Br J Cancer 2012;107:1901-7.

34. Del Giudice ME, Grunfeld E, Harvey BJ, Piliotis E, Verma S. Primary care physicians' views of routine follow-up care of cancer survivors. J Clin Oncol 2009;27:3338-45.

35. Status of the medical oncology workforce. The American Society of Clinical Oncology. J Clin Oncol 1996;14;2612-21.

36. Keating NL, Landrum MB, Guadagnoli E, et al. Factors related to underuse of surveillance mammography among breast cancer survivors. J Clin Oncol 2006;24:85-94.

37. Grunfeld E, Dhesy-Thind S, Levine MN. Fol- low-up after treatment for breast cancer-summary of the 2005 update. Can Med Assoc J 2005;172: $1319-20$.

38. Zitzelsberger L, Grunfeld E, Graham I. Family physicians' perspectives on practice guidelines related to cancer control. BMC Fam Pract 2004;5:25.

39. Bober SL, Recklitis CJ, Campbell EG, et al. Caring for cancer survivors: a survey of primary care physicians. Cancer 2009;115(18 Suppl):4409-18.

40. Desch CE, Benson AB, Smith TJ, et al. Recommended colorectal cancer surveillance guidelines by the American Society of Clinical Oncology. J Clin Oncol 1999;17:1312-21.

41. Hudson SV, Miller SM, Hemler J, et al. Adult cancer survivors discuss follow-up in primary care: "Not what I want, but maybe what I need." Ann Fam Med 2012;10:418-27.

42. Nissen MJ, Beran MS, Lee MW, et al. Views of primary care providers on follow-up care of cancer patients. Fam Med 2007;39:477-82.

43. Kantsiper M, McDonald EL, Geller Gail, et al. Transitioning to breast cancer survivorship: perspectives of patients, cancer specialists, and primary care providers. J Gen Intern Med 2009;24(Suppl 2):S459-66.

44. Ganz PA, Hahn EE. Implementing a survivorship care plan for patients with breast cancer. J Clin Oncol 2008;26:759-67.

45. Owusu GA, Eve SB, Cready CM, et al. Race and ethnic disparities in cervical cancer screening in a safety-net system. Matern Child Health J 2005;9: 285-95.

46. National Center for Health Statistics. DATA 2010. . The Healthy People 2010 Database. May 2008 edition. Available from: http://wonder.cdc.gov/ data2010/. Accessed October 23, 2012.

47. Suneja G, Diaz JA, Roberts M, Rakowski W. Reversal of associations between Spanish language use and mammography and Pap smear testing. J Immigr Minor Health 2013;15:255-61.

48. Rodríguez MA, Ward LM, Pérez-Stable EJ. Breast and cervical cancer screening: impact of health insurance status, ethnicity, and nativity of Latinas. Ann Fam Med 2005;3:235-41.

49. Cook N, Kobetz E, Reis I, Fleming L, Loer-Martin $\mathrm{D}$, Amofah SA. Role of patient race/ethnicity, insurance and age on Pap smear compliance across ten community health centers in Florida. Ethn Dis 2010; 20:321-6.

50. Adams EK, Florence CS, Thorpe KE, Becker ER, Joski PJ. Preventive care: female cancer screening, 1996-2000. Am J Prev Med 2003;25:301-7.

51. US Cancer Statistics Working Group. United States cancer statistics: 1999-2005 incidence and mortality webbased report. Atlanta, GA: US Department of Health and Human Services, Centers for Disease Control and Prevention, National Cancer Institute; 2009.

52. White K, Garces IC, Bandura L, McGuire AA, Scarinci IC. Design and evaluation of a theory-based, 
culturally relevant outreach model for breast and cervical cancer screening for Latina immigrants. Ethn Dis 2012;22:274-80.

53. O’Brien MJ, Halbert CH, Bixby R, Pimentel S, Shea JA. Community health worker intervention to decrease cervical cancer disparities in Hispanic women. J Gen Intern Med 2010;25:1186-92.

54. Watts L, Joseph N, Velazquez A, et al. Understanding barriers to cervical cancer screening among Hispanic women. Am J Obstet Gynecol 2009;201: 199.e1-8.
55. Elit L, Saskin R, Raut R, Elliott L, Murphy J, Marrett L. Sociodemographic factors associated with cervical cancer screening coverage and follow-up of high grade abnormal results in a population-based cohort. Gynecol Oncol. 2013;128:95-100.

56. Guilfoyle S, Franco R, Gorin SS. Exploring older women's approaches to cervical cancer screening. Health Care Women Int 2007;28:930-50.

57. Liu Y, Diamant AL, Thind A, Maly R. Validity of self-reports of breast cancer treatment in lowincome medically underserved women with breast cancer. Breast Cancer Res Treat 2010;119:745-51. 